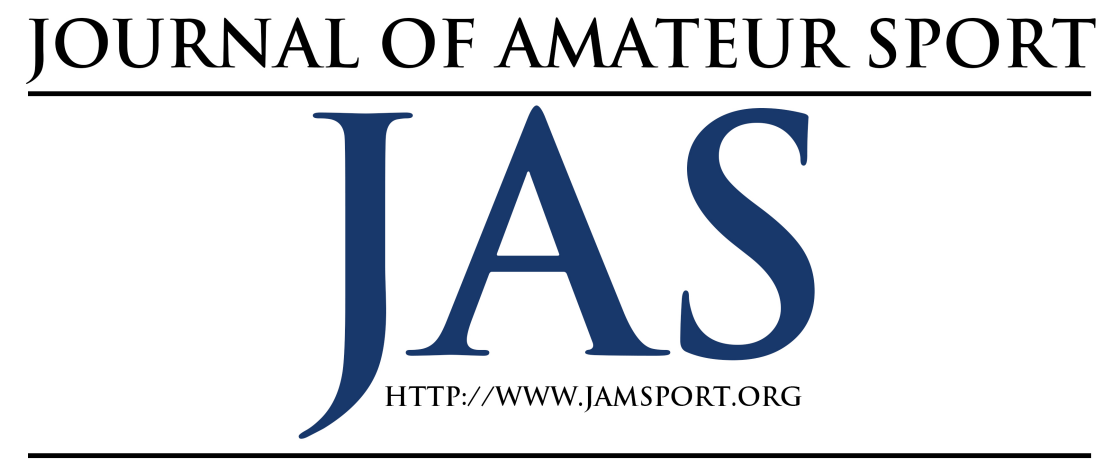

\title{
Female Roller Derby Athletes' Athletic Identity and Systematic Pursuit of Leisure
}

\author{
Hung-Ling Liu ${ }^{1}$ \\ Michael Bradley ${ }^{3}$ \\ ${ }^{1}$ South Dakota State University
${ }^{2}$ Oklahoma State University
${ }^{3}$ Eastern Kentucky University
}

Timothy Baghurst ${ }^{2}$

Athletic identity is a foundational element of an individual's self-concept and affects psychological, social, and behavioral characteristics. The purpose of this study was to investigate a women-dominated sport, roller derby, by exploring the relationships between athletic identity of women athletes and serious leisure pursuit in the sport. Participants were 578 women registered with the Women's Flat Track Derby Association (WFTDA) who completed an online survey regarding their athletic identity. Hierarchical multiple regression analysis showed demographic variables (family income) were a minor predictor of participants' serious leisure pursuit. Internal and external components of athletic identity were positively associated with participant's level of serious leisure, while internal components (i.e. self-identity and positive affectivity) were stronger in predicting women athletes' systematic leisure pursuit in roller derby than external ones. Results of this study support that roller derby provides an opportunity for women to enjoy a full-contact sport and develop identity as an athlete with strength and knowledge through their systematic leisure pursuit. Furthermore, findings suggest promoting roller derby programs or other untraditional female sports may foster greater engagement and greater commitment to sport and facilitate equality for women in sports.

S

port provides a salient, visible, and accessible venue to create a self-image and self-identity in Western society. Athletic-related identities have received much attention in sports phenomena studies, including athlete and fan identity in sports. Studies of athletic identity have focused primarily on professional and 
collegial athletes' career development and maturity (Lally \& Kerr, 2005; Murphy, Petitpas, \& Brewer, 1996), student-athlete identity conflicts (Yopyk \& Prentice, 2005), and coping with career transition or retirement (Grove, Lavallee, \& Gordon, 1997). In part because sports are generally considered to be activities for young, middle-class, and white men (Henderson, Hodges, \& Kivel, 2002; Kay, 2000; Lim et al., 2011), little research has been conducted to understand the women and minority perspective of leisure pursuits in sports. Therefore, it is important to understand women's perspective of athletic identity in assisting them to gain personal, physical, and psychological empowerment through sport in their leisure time (Dilley \& Scraton, 2010; Heuser, 2005; Mennesson, 2000).

Roller derby is a female-dominated sport that is aggressive and incorporates body contact into competition. The philosophy of roller derby, "by the skaters, for the skaters" (Beaver, 2012, p.25), illustrates a do-it-yourself ethos where women athletes are typically owners, managers, and/or operators of their own leagues while following rules, safety, and guidelines for national and international competition (Women's Flat Track Derby Association, 2012). With high speed skating, and players alternating offense and defense positions constantly, the game is physical, competitive, and risky (Carlson, 2010). Historically, the sport of roller-skating and roller derby spinning started in the nineteenth century and became a gender- liberating symbol in sport history (Pavlidis, 2012). Roller derby is a high intensity and full contact sport, providing women an activity and space that challenges them to use their body instrumentally and offers an alternative way of experiencing their body (Storms, 2008).

Although there are a few studies that have investigated roller derby, research is limited (Eklund \& Masberg, 2014; Eklund, \& Masberg, 2015; Paul \& Blank, 2015). For example, the majority of existing studies have applied ethnographical methods or qualitative approaches, such as observation, in-depth interviews, field studies, and casestudy research. Using a quantitative approach with a larger number of research participants may provide insight into the psychological engagement and social adaptations of women athletes in roller derby from a larger scale and use a quantitative approach to connect with other related theories for future studies (Gould, Moore, McGuire, \& Stebbins, 2008). Therefore, the purpose of this study was two-fold: (1) to investigate how internal and external athletic identity affected level of seriousness in participating in roller derby with a large sample size, and (2) to explore whether demographics affect leisure pursuit in the sport.

\section{Literature Review}

Identity can be defined as "parts of a self-composed of the meanings that persons attach to the multiple roles they typically play in highly differentiated contemporary 
societies" (Stryker \& Burke, 2000, p.284). The concept has been discussed within structural and cognitive identity theories. Structural identity theory focuses on the influence of external/social components, such as society and groups, while internal/personal identity theory explores the effects of internal components on individuals' evaluation of themselves (Stryker \& Burke, 2000). Luhtanen and Crocker (1992) stated that "whereas personal identity refers to how people view themselves as individuals, social identity refers to how they view the social groups to which they belong" (p. 302). Social identity can derive from a variety of group memberships, including family, friends, colleagues, or groups based on race, gender, and occupation. For example, college students might identify themselves based on their internal value of potential and individual qualities, while values may be formed through relevant social groups and significant others, such peers, parents, and coaches. Social structure and self-evaluation affect behavior in addition to internal and external self (Cieslak, 2004; Green, 2001; Stryker \& Burke, 2000).

Athletic identity is a key component of the self-concept of an individual athlete and is relevant to psychological, social, and behavioral characteristics (Martin, Eklund, \& Mushett 1997; Nasco \& Webb, 2006). The initial athletic identity was treated as a single-dimension theory; whereas later, most researchers adopted a multidimensional approach to examine an individual's thoughts and feelings toward their athlete role as an aspect of life with personal and social factors (Horton \& Mack, 2000). Previous research identified several dimensions of internal and external identity; (1) Social identity refers to the degree in which an individual views him/herself as an athlete from a social standpoint; (2) Exclusivity reflects the degree to which individuals rely heavily on their athletic role or performance to determine their value as a person; (3) Self-identity captured the strength of an individual's self-referred him/herself as an athlete; (4) Negative affectivity emphasized the negative experience of individual's sports-related performance and outcomes (i.e., injury); and (5) Positive affectivity emphasized the positive and desirable outcomes of individuals' sport participation (Brewer, Van Raalte, \& Linder, 1993; Cieslak, 2004; Jun \& Kyle, 2012; Martin et al., 1997; Phoenix, Faulkner, \& Sparkes, 2005).

\section{Athletic Identity for Women in Sport}

It is necessary to understand the significance of sport and exercise for women and the effects of sport on their sense of identity in a male-dominated field (Messner, 2002; Paul, 2015). In general, participation in sports is an opportunity for women to gain empowerment, in spite of the social, political, and economic realities that have limited their opportunities to acquire facilities, opportunities, and legitimacy as athletes (Raisborough, 2006; Ross \& Shinew, 2008; Wachs, 2005). 
Although athletic identity has been used to understand athletes' view and identification in their sports engagement, only a few studies have focused on women's athletic identity in sports. Mean and Kassing (2008) reported that women athletes wanted to be identified as athletes based on their athletic ability and performance rather than gender alone. They also experienced limited avenues and resources available to establish their athletic identity as women compared to their male counterparts. In addition, Ross and Shinew (2008) found that female athletes were viewed (by others) as serious competitors with pride and well-developed athletic skills.

A few other studies have focused on amateur and recreational women athletes' identity with sports or adventure recreation. In research by Lamont-Mills and Christensen (2006), several patterns of athletic identity between level of sport participation among women and men athletes were identified: (1) elite women athletes indicated a higher athletic identity from others (social identity) and relied on their athletic role to determine who they are (exclusivity) than did recreational and nonparticipation women athletes; (2) only elite men's athletes scored higher in social identity than their women counterparts; and (3) athletes from different gender and level of improvement experienced similar negative affectivity in the sports they chose. In other words, athletic identity has showed variation by gender and level of sport involvement.
Through interviewing women's flag football tournament participants, Green (2001) found that participants were attracted to the sport by the physical nature of the game and enjoyed having a space to share and celebrate their identity as women football players. Heuser (2005) found that the social nature of competitive sports created a community for women sharing similar interests, experiences, challenges, and a sense of accomplishment. Women athletes and adventurists are aware they can negotiate and prioritize time and space for pursuing sport and recreation to receive and reinforce benefits from the experience (Little, 2002). These outcomes reinforced their sport identities associated with the activity and developed a career-like involvement.

\section{Serious Leisure Theory}

The theory of serious leisure was originally defined by Stebbins (1992):

The systematic pursuit of an amateur, hobbyist, or volunteer activity that people find so substantial and interesting, and feeling that, in typical cases, they launch themselves on a (leisure) career on acquiring and expressing a combination of its special skills, knowledge, and experience (Stebbins, 2006, p. 3).

Stebbins formulated the theory through ethnographic research involving musicians, actors, archeologists, baseball players, astronomers, entertainment magicians, football players, and stand-up comics. 
Through systematic pursuit in leisure, people are enabled to develop their confidence, self-esteem and gain close friendship, lifelong learning experiences, and personal growth opportunities (Brown, McGuire, \& Voelkl, 2008; Patterson \& Pegg, 2009). Serious leisure has been viewed as a profound, consistent, invariable engagement based on substantial knowledge and skills, and also requires more perseverance to overcome challenges and complex tasks. Within this type of leisure experience, people feel deep satisfaction and experience a full existence (Stebbins, 2001).

Serious leisure has been defined by six distinguished qualities (Stebbins, 2006). Participants acquire perseverance to overcome psychological and physical difficulties during their experiences (i.e., anxiety, embarrassment, and physical dangers). Participants embark upon a leisure career in the endeavor to improve their engagement shaped by special contingencies and turning points of achievement or involvement. Participants require significant personal effort for earning special skills, knowledge, and training, all of which require more learning opportunities outside of formal education, or through a self-directed learning process. A variety of durable benefits through serious leisure pursuit have been discussed, such as self-actualization, self-image, social interaction, belongingness, and physical and mental health in various studies (i.e., Dilley \& Scraton, 2010; Heo, Stebbins, Kim, \& Lee, 2013; Lamont, Kennelly, \& Moyle, 2014; Tsaur \& Liang, 2008). Participants also tend to identify strongly with their chosen activity and engage with the unique ethos within the social group and community of activity.

\section{Roller Derby Identity Through Systematic Leisure Pursuit}

In studying individuals' leisure pursuit in sports, the theory of serious leisure is regularly used to explore characteristics of amateur athletes pursuing their leisure systematically and acquiring benefits from the process (Stebbins, 1992). Stebbins (2001) stated that "every serious leisure activity offers a major lifestyle and identity for its enthusiasts (p.56)." Although roller derby is considered a form of sport and fits within the context of serious leisure, several views exist that challenge this idea. While roller derby might face opposition for being viewed as a sport from outsiders, roller derby participants claim and play it as a sport "for real" or a legitimate sport with risky factors (Carlson, 2010, p. 436).

Like other leisure experiences, roller derby participants freely choose personally meaningful engagement and to make a strong commitment to enjoy the sport. This helps facilitate participant leisure identity development and career-like progression in the sport (Heo \& Lee, 2010; Raisborough, 2006 Stebbins, 2001). In understanding roller derby participants' involvement and dedication to the sport, several studies (Beaver, 2012; Eklund \& Masberg, 2014; Paul, 2015; Pavlidis \& Fullagar, 2015; Raisborough, 2006) have shown a 
substantial connection with the concept of serious leisure through the six distinguished qualities of serious leisure developed by Stebbins (1992), including: (1) perseverance, (2) a leisure career in their endeavor, (3) significant personal effort, (4) durable benefits, (5) unique ethos within the activity, and (6) strong identification with the chosen activity. For example, many roller derby participants wear their bruises and scars with pride and celebrate injury as an honor to the sport (Paul, 2015; Pavlidis \& Fullagar, 2015; Storms, 2008), all of which enhance their internal identity as roller derby women and create a community to enable them to enforce their external identity through friendship and sense of belongingness (Fagundes, 2014).

Women athletes tend to show strong identification with roller derby. The "do it yourself" operation of roller derby league maintains and manages participants' athletic activity and organization and serves to protect the sport as a whole. It creates an alternative to differentiating between sports and a lifestyle creation, which defines the uniqueness of the sport and creates a space for women to develop their identity on and off the track (Beaver, 2012; Messner, 2002).

Other than as a sport, roller derby participants have created subcultures within the sport, such as music and fashion (Carlson, 2010; Pavlidis, 2012). Roller derby has its own artistic sensibilities toward outfits and make-up, whereby female athletes dramatically express their own individuality and identity (Paul, 2015).
Popular music is also part of the creative assemblage in roller derby (Pavlidis, 2012). Roller derby women athletes are able to create their roller derby identity individually and collectively as a team (Pavlidis \& Fullager, 2012; Raisborough, 2006) and reinforce their established identity in this competitive sport (Dionigi, 2002; Green, 1998).

The close relationship between serious leisure and athletic identity has been discussed in various sports, including swimming (Hastings, Kurth, Schloder, \& Cyr, 1995), running (Goff, Fick, \& Oppliger, 1997), and golfing (Siegenthaler \& O'Dell, 2003). The strong identity associated with athletes is an evolving process of systematic involvement in sports where individuals are able to acquire a sense of being an athlete with who they are and how they want others to view them (Green \& Jones, 2005; Kane \& Zink, 2004; O'Connor \& Brown, 2010; Stebbins, 2006). This process results in a reinforcing cycle of strengthening individuals' athletic identity and accruing benefits from the sport of their choice. Such benefits include enhancing personal confidence and selfesteem, fostering friendships, and creating lifelong and personal learning experiences (Brown et al., 2008; Dilley \& Scraton, 2010; Dionigi, 2002; Patterson \& Pegg, 2009).

Only a few studies have explored the relationship between serious leisure and athlete identity in women through a quantitative approach. Various qualitative studies have indicated that women athletes 
increase their sports self-concept and empower personal identity and body through leisure spaces and experiences (Baghurst, Parish, \& Denny, 2014; Bartram, 2001; Gillespie, Leffler, \& Lerner, 2002; Mennesson, 2000; Raisborough, 2006). Roller derby women athletes are able to create their roller derby identity individually and collectively, (Pavlidis \& Fullager, 2012; Raisborough, 2006) and reinforce their established identity in this competitive sport (Dionigi, 2002; Green, 1998). As a womencentered sport, roller derby offers a unique research opportunity to better understand how women experience and explore internal and external identity through their leisure pursuits (Ross \& Shinew, 2008).

\section{Method \\ Sampling and Data Collection}

The population of the study consisted of roller derby competitors registered in the Women's Flat Track Derby Association (WFTDA) in the United States. Researchers collected 2037 e-mail addresses from the WFTDA online database (84 of which were invalid). An email invitation was sent out to 1953 usable email addresses, and 578 women roller derby athletes responded and completed the web-based survey. The survey remained available for four weeks in September of 2012. There was no follow-up invitation or reminder. Prior to data collection, the Institutional Review Board (IRB) at a south-central university in the United States approved the study.

\section{Instruments}

\section{Serious Leisure Inventory and} Measurement (SLIM). A modified version (Gould et al., 2011) of the Serious Leisure Inventory and Measurement (SLIM; Gould et al., 2008) was used to measure amateur roller derby participants' level of involvement and personal durable outcomes. This 18-item instrument closely adhered to Stebbins's theoretical concept of amateur athletics' leisure pursuit (Gould et al., 2011). Respondents rated each item of the SLIM using a five-point scale from one, strongly disagree, to five, strongly agree, where a higher subscale score indicates a higher level of serious leisure pursuit. An average mean score of these items was calculated as a dependent variable for assessing roller derby participants' level of involvement.

\section{Athletic Identity Measurement Scale} (AIMS-Plus). The Athletic Identity Measurement Scale-Plus is one of the most popular instruments to assess elite and amateur athletes in sport psychology (Brewer \& Cornelius, 2001; Cieslak, 2004; Jun \& Kyle, 2012). Nineteen items of AIMS were used to measure participants' selfdetermined identity with the sport, including social identity (5 items), exclusivity (5 items), self-identity (3 items), negative affectivity ( 2 items), and positive affectivity (4 items). Respondents rated each item using a five-point scale from one, strongly disagree, to five, strongly agree, where a higher subscale score indicates a higher level of self-identification on each dimension. 
Each sub-dimension of athletic identity was calculated as an independent variable.

\section{Demographics and behavioral}

patterns. Other general demographic information was collected including age (18-34; 35-54; 55+), education level (less than Bachelors; Bachelor's degree and above), race (white; non-white), and household annual income $(<\$ 55,000 ; \geq$ $\$ 55,000)$. Additional information specific to roller derby was collected to understand participants' engagement with the sport. Examples included whether participants were members of a roller derby organization, the frequency of their practices (several times per week, once per week, once per two weeks, once per month, and once every few months), and the numbers of participated bouts (match between two teams) in which they had competed in the past year.

\section{Data Analysis}

Descriptive analysis was used to report demographics of research participants, and a Pearson's $r$ correlation was used to examine correlations between the dependent variable (serious leisure) and independent variables (demographics and athletic identity). The researchers used a hierarchical multiple regression to examine how well the set of independent variables (demographics and athletic identity) predicted the probability of women engaging in roller derby as a serious leisure pursuit and to determine if athletic identity improved the prediction of systemic pursuit of leisure above their demographics. Following the sequence, the first multiple regression model included four demographics (dichotomous variables): age, education, annual family income, and race. The second regression model added five athletic identity variables for predicting roller derby participants' level of seriousness. Tolerance and variance inflection factor (VIF) were utilized to diagnose multicollinearity among independent variables; all independent variables had a tolerance greater than .40 and VIF of less than 10 (Vaske, 2008). The Cronbach's alpha of the serious leisure variable and five sub-dimensions of athletic identity ranged from .68 (negative affectivity, 2 items) to .94 (serious leisure, 18 items). An alpha level of 0.05 significance was used in this study.

\section{Results}

The majority of participants ranged in age from 18 to 34 years old $(69 \%)$ and no participants reported they were 55 or older. Slightly more than two-thirds $(68.2 \%)$ of participants had a Bachelor's degree or higher. Ninety-three percent of research participants were Caucasian/White, while other ethnic groups were relatively small. Over two-thirds of participants had an individual membership with WFTDA. Almost all (98\%) practiced once a week, and no participants reported their practice less than once a week. Participants reported competing on average 13 times over the previous year; 7 at home and 6 away. Table 
1 reports the demographic and behavioral profile of participants. The average score of serious leisure (SLIM) was 4.24, while the average score of athletic identity factors ranged from 3.76 to 4.42 , in which Positive affectivity was the highest score and Exclusivity the lowest (Table 2).

The correlation between serious leisure, demographics, and athletic identity is shown in Table 2. Serious leisure was negatively correlated with education level $(r=-.11, p$ $<.01)$ and family annual income $(r=-.16, p$ $<.01)$. Among the demographics, participants' age was negatively correlated with education $(\mathrm{r}=-.09, p<.05)$ and positively correlated with family income $(r=$ $.27, p<.01)$. Roller derby participants' level of serious leisure was positively correlated with their athletic identity, ranging from .16 (negative affectivity) to .64 (positive affectivity). Positive correlations between athletic identity variables were between .18 and .61.

A two-step hierarchical regression investigated how well the set of independent variables (demographics and athletic identity) predicted participants' probability of engaging in the sport as a serious leisure pursuit, and to determine if the addition of demographic variables improved the prediction of serious leisure. Table 3 shows the detailed results of each regression model. Results of the first model $\left[R^{2}=.04, F(4,573)=5.51, p<.001\right]$ indicated that participants' demographic variables accounted for $4 \%$ of their serious leisure in roller derby. Annual family income and education level were statistically significant in this model, respectively $(\beta=$ $.16, p<.001 ; \beta=-.10, p=.02)$.

The second model used demographics and athletic identity to predict roller derby participants' serious leisure pursuit which showed a statistically significant relationship $\left[R^{2}=.65, F(5,568)=200.07, p<.001\right.$; adjusted $\left.R^{2}=.65\right]$. The addition of athletic identity to the prediction of level of seriousness in leisure led to a statistically significant increment in $\mathrm{R}^{2}$ of $.61, p<.001$. Within the second model, all five athletic identity variables were statistically significant, including positive affectivity $(\beta=$ $.50, p<.001)$, self-identity $(\beta=.26, p<$ $.001)$, exclusivity $(\beta=.13, p<.001)$, social identity $(\beta=.09, p=.003)$, and negative affectivity $(\beta=-.08, p=.005)$. Annual family income was the only demographic variable that remained statistically significant in the second model $(\beta=-.07, p=.012)$.

\section{Discussion}

This study represents an initial exploration of the relationship between roller derby participation as a systematic leisure pursuit and its association with demographics and athletic identity through a quantitative approach. The characteristics of roller derby women participating in the study were similar to those reported in the WFTDA's demographic survey (2012) and previous roller derby studies (Beaver, 2012; Carlson, 2010; Eklund \& Masberg, 2014). The majority of roller derby participants in the United States are White/Caucasian, 
between the ages of 25 and 45 , have a fouryear college degree, and have an annual household income of about $\$ 55,000$ (WFTDA, 2012).

In the present study, participants' education and income were negatively correlated with their level of serious leisure in the sport, indicating that participants with a higher income and education reported a less serious involvement in the sport. However, there was a positive correlation between roller derby participants' age and income, suggesting that the women athletes between the age of 35 and 54 were more likely to have higher annual income than the younger group. It is possible that the younger roller derby women may have attained a higher education/degree, but their annual income was lower because of the length of their working history.

Although household income, a demographic variable, was significant in the final hierarchical regression model, it is relatively minimal compared to other psychological variables (i.e., athletic identity variables) in predicting roller derby participants' consistency and dedication in their leisure pursuit.

This study expanded upon previous qualitative research by supporting the connection between athletic identity and serious leisure (Green \& Jones, 2005; Kane \& Zink, 2004; Stebbins, 2006). All five athletic identity variables (two external variables and three internal variables) significantly predicted roller derby participants' serious leisure pursuit. This result confirmed that internal/self-identity and external/social identity are important for individuals to form and define "who they are" as athletes (Anderson \& Taylor, 2010; Hurst, Hale, Smith, \& Collins, 2000; Stryker \& Burke, 2000). The results also showed that women roller derby participants' internal identity factors, such as self-identity and positive identity, were stronger predictors than external factors in responding to their level of systematic leisure pursuit. Similar to other roller derby studies, roller derby women exhibit a strong will and identity in the sport, and could their leisure participation as a space for them to develop internal identity outside of their traditional role in the family (Dionigi, 2002; Green, 1998; Pavlidis \& Fullager, 2013; Raisborough, 2006).

The results of the study also revealed that participants showed the strongest association with the sport through their internal athletic identity components, including positive affectivity and selfidentity. Positive affectivity (personal rewards) have been the most substantial variable to predict serious leisure participants (Misener, Doherty, \& HammKerwin, 2010). It is possible that leisure as the central aspect of participants' lives provides an opportunity for women to empower their internal identity and establish social identities within the sport community and with those who understand the benefits and culture of the sport (Brown et al., 2008; Dilley \& Scraton, 2010; Kane \& Zink, 2004; Raisborough, 2006). Regardless of external 
identification from outsiders, internal identity in relation to the sport and as athletes might be more important for participants' systematic pursuit and longterm commitment to roller derby.

Using regression analysis, another contribution from the study was finding a negative coefficient between serious leisure and negative affectivity, meaning negative outcomes are not actually "negative" effects to roller derby participants. The result was unexpected, as in general, athletes tend to experience high negative outcomes when they have a high expectation for their performance and do not meet those expectations (Brewer, Shelby, Linder, \& Petitpas, 1999; Tasiemski \& Brewer, 2011). It is possible that an amateur athlete's ability to transform a negative or unpleasant experience into a positive practice may help explain a long-term dedication of systematic pursuit rather than being worried about professional career and livelihood. As Raisborough (2006) stated, amateur athletes tend to "structure their lives in such way to privilege their time and resources for their serious leisure" (p. 245).

Although these findings make a unique contribution to the understanding of women roller derby participants in the serious leisure context, there are several limitations in the study, which may provide opportunities for further inquiry.

Convenience sampling and a single email invitation was the only approach used to recruit potential research participants. This approach might contain some biases in the results. Such biases may include underrepresentation or overrepresentation of particular groups and issues related to internet access or responding to a survey online.

Having electric and paper-based questionnaires with random sample techniques might be helpful for including a more diverse roller derby sample and a better ability to generalize results to the entire population. It also could be beneficial to study the leisure constraints of different age groups to investigate whether motivations for participation differ by age. Additionally, most research participants were in a roller derby group/league, which may result in a higher level of seriousness in their participation in the sport.

Demographic variables were included in this model to investigate the difference between amateur athletes in serious leisure context. However, a limited choice of demographic items might contain some restrictions to the results. Some additional variables should be considered for future studies: (1) demographic variables such as marital status, with or without children, and physical condition; and (2) additional behavioral variables, such as years of involvement in roller derby, skill-level, money spent on roller derby, distance traveled to practice or compete, and lifestyle alteration for the sport. It might be beneficial to apply the recreation specialization theory to explore how amateur roller derby participants gain a career-like experience and to examine 
recreationalists' cognitive development through sport, such as motivation and satisfaction (Needham, Scott, \& Vaske, 2013; Scott, 2012; Tsaur \& Liang, 2008).

This may increase the understanding of how to foster roller derby participants' dedication in leisure pursuit and assist to promote a supportive environment for women to enjoy physical activities and sports as their leisure pursuit in general.

Finally, research participants did not intrinsically define themselves as serious leisure participants. The researchers defined Serious Leisure by the participants' SLIM score: a higher the score showed a higher level of seriousness. It might be helpful to include women roller derby participants' perspective on leisure and their experience in systematically pursuing roller derby as their leisure activity for further understanding their free time use as serious leisure participants and their identity with the sport.

\section{Conclusion}

This study supports roller derby, a women-dominated sport, as a serious sport and leisure space for women to develop their identity as women and as athletes. Roller derby could help women gain physical skills and a sense of pride through their leisure pursuit and their own identity (Carlson, 2010; Messner, 2002; Paul, 2015; Pavlidis, 2012; Ross \& Shinew, 2008). This study utilized a quantitative approach and sampling with a larger participant pool than previous studies in roller derby. The researchers then explored the relationship between serious leisure and athletic identity for a better understanding of how women athletes' dedication and embodied experiences through sport participation. Although roller derby might struggle to be viewed as a sport from outsiders (Breeze, 2013), roller derby participants showed a strong commitment and career-like progression in gaining the knowledge and skills necessary to be successful at the sport.

Applying a multidimensional construct to study athletic identity might provide an insight to understanding how roller derby women athletes define themselves and construct their identity through the sport (Lamont-Mills \& Christensen, 2006; Ryska, 2002). The study revealed that women roller derby participants' serious leisure pursuit was positively associated with their internal/personal and external/social identities as an athlete. Internal or personal components of athletic identity that are associated with roller derby are the most significant formation and preservation avenue for women athletes in creating their own identity as athletes in the competitive and full-contact sport. In addition, external or social components of athletic identity tend to influence how they evaluate and interpret their identity through a social context (Jun \& Kyle, 2012; Martin et al., 1997; Stryker \& Burke, 2000). Although internal and external components are important for an individual to define, maintain, and reinforce their identity as an athlete, in general, internal identity 
components are stronger predictors than external ones.

This study also found that amateur athletes or recreation sport participants might gain a strong sense of self and positive psychological benefits, much like elite athletes, through their leisure pursuits. The results of this study suggest offering promotion for roller derby programs or contact sports (i.e., boxing, football) to foster women's engagement and a greater commitment to sport. This might create a space for women to redefine who they are and what they can do through sport participation, as well as facilitate equality for women in sports.

In order to promote roller derby as a sport for younger generations, women roller derby leagues could assist junior roller derby leagues by starting leagues/bouts, creating modified derby rules, safety training, and advancing skills of the sport (Cathorall \& Puches, 2017). By doing so, it is possible to help the public understand the positive effects for roller derby participants physically and psychologically and alter negative stereotypes and restrictions for women participating in competitive sports and leisure pursuits (Dilley \& Scraton, 2010; Paul, 2015; Roster, 2007). 


\section{References}

Anderson, L., \& Taylor, J. D. (2010).

Standing out while fitting in: Serious leisure identities and aligning actions among skydivers and gun collectors. Journal of Contemporary Ethnography, 39(1), 34-59.

Baghurst, T., Parish, A., Denny, G. (2014). Why women become competitive amateur bodybuilder. Women in Sport and Physical Activity, 22, 5-9.

Bartram, S. A. (2001). Serious leisure careers among whitewater kayakers: A feminist perspective. World Leisure Journal, 43(2), 4-11.

Beaver, T. D. (2012). "By the skaters, for the skaters" The DIY ethos of the roller derby revival. Journal of Sport and Social Issues, 36(1), 25-49.

Breeze, M. (2013). Analyzing seriousness' in roller derby: Speaking critically with the serious leisure perspective. Sociological Research Online, 18(4), 23.

Brewer, B. W, Shelby, C. L., Linder, D. E. \& Petitpas, A. J. (1999). Distancing oneself from a poor season:

Divestment of athletic identity. Journal of Personal and Interpersonal Loss, 4, 149-162.

Brewer, B. W., \& Cornelius, A. E. (2001).

Norms and factorial invariance of the Athletic Identity Measurement Scale. Academic Athletic Journal, 15(2), 103 113.

Brewer, B. W., Van Raalte, J. L., \& Linder, D. E. (1993). Athletic identity: Hercules' muscles or achilles heel?
International Journal of Sport Psychology, 24, 237-254.

Brown, C. A., McGuire, F. A., \& Voelkl, J. (2008). The link between successful aging and serious leisure. The International Journal of Aging and Human Development, 6(1), 73-95.

Carlson, J. (2010). The female significant in all women's amateur roller derby. Sociology of Sport Journal, 27(4), 428440.

Cathorall, M. L., \& Punches, M. (2017). Descriptive study of female roller derby athletes' beliefs about risk factors for injury in roller derby. BMJ Open Sport \& Exercise Medicine, 3(1), 1-5. doi:10.1136/bmjsem-2017000294.

Cieslak II, T. J. (2004). Describing and measuring the athletic identity construct: Scale development and validation (Doctoral dissertation). Retrieved from https:// etd.ohiolink.edu.

Dilley, R. E., \& Scraton, S. J. (2010).

Women, climbing and serious leisure. Leisure Studies, 29(2), 125-141.

Dionigi, R. (2002). Leisure and identity management in later life: Understanding competitive sport participation among older adults. World leisure journal, 44(3), 415.

Eklund, A., \& Masberg, B. A. (2014). Participation in roller derby, the influence on body image. Clothing and Textiles Research Journal, 32(1), 49-64. 
Eklund, A., \& Masburg, B. A. (2015). International female perspective on roller derby and body image. World Journal of Social Science Research, 2(1), 104-127.

Fagundes, D. (2014). Labor and/as Love: Exploring the commons of roller derby. In Frischmann, B. M., Madison, M. J. \& Strandburg, K. J. (Eds.), Governing Knowledge Commons, (pp. 417-444). New York, NY:

Oxford University Press.

Gillespie, D. L., Leffler, A., \& Lerner, E. (2002). If it weren't for my hobby, I'd have a life: Dog sports, serious leisure, and boundary negotiations. Leisure Studies, 21(3-4), 285-304.

Goff, S. J., Fick, D. S., \& Oppliger, R. A. (1997). The moderating effect of spouse support on the relation between serious leisure and spouses' perceived leisure-family conflict. Journal of Leisure Research, 29(1), 4760.

Gould, J., Moore, D., Karlin, N. J., Gaede, D. B., Walker, J., \& Dotterweich, A. R. (2011). Measuring serious leisure in chess: Model confirmation and method bias. Leisure Sciences, 33(4), 332-340.

Gould, J., Moore, D., McGuire, F., \& Stebbins, R. (2008). Development of the serious leisure inventory and measure. Journal of Leisure Research, 40(1), 47-68.
Green, B. C. (2001). Leveraging subculture and identity to promote sport events. Sport Management Review, 4(1), 1-19.

Green, B. C., \& Jones, I. (2005). Serious leisure, social identity and sport tourism. Sport in Society, 8(2), 164-181.

Green, E. (1998). 'Women doing friendship': An analysis of women's leisure as a site of identity construction, empowerment and resistance. Leisure Studies, 17(3), 171185.

Grove, J. R., Lavallee, D., \& Gordon, S. (1997). Coping with retirement from sport: The influence of athletic identity. Journal of Applied Sport Psychology, 9(2), 191-203.

Hastings, D. W., Kurth, S. B., Schloder, M., \& Cyr, D. (1995). Reasons for participating in a serious leisure career: Comparison of Canadian and U.S. masters swimmers. International Review for the Sociology of Sport, 30(1), 101-119.

Henderson, K. A., Hodges, S., \& Kivel, B. D. (2002). Context and dialogue in research on women and leisure. Journal of Leisure Research, 34(3), 253. Heo, J., \& Lee, Y. (2010). Serious leisure, health perception, dispositional optimism, and life satisfaction among senior games participants. Educational Gerontology, 36(2), 112-126.

Heo, J., Stebbins, R. A., Kim, J., \& Lee, I. (2013). Serious leisure, life satisfaction, and health of older adults. Leisure Sciences, 35(1), 16-32. 
Heuser, L. (2005). We're not too old to play sports: The career of women lawn bowlers. Leisure Studies, 24(1), 45-60.

Horton, R., \& Mack, D. (2000). Athletic identity in marathon runners: Functional focus or dysfunctional commitment? Journal of Sport Behavior, 23(2), 101-119.

Hurst, R., Hale, B., Smith, D., \& Collins, D. (2000). Exercise dependence, social physique anxiety, and social support in experienced and inexperienced bodybuilders and weightlifters. British Journal of Sports Medicine, 34(6), 431435.

Jun, J., \& Kyle, G. T. (2012). Gender identity, leisure identity, and leisure participation. Journal of Leisure Research, 44(3), 353-378.

Kane, M. J., \& Zink, R. (2004). Package adventure tours: Markers in serious leisure careers. Leisure Studies, 23(4), 329-345.

Kay, T. (2000). Leisure, gender and family: The influence of social policy. Leisure Studies, 19(4), 247-265.

Lally, P. S., \& Kerr, G. A. (2005). The career planning, athletic identity, and student role identity of intercollegiate student athletes. Research Quarterly for Exercise and Sport, 76(3), 275-285.

Lamont, M., Kennelly, M., \& Moyle, B. (2014). Costs and perseverance in serious leisure careers. Leisure Sciences, 36(2), 144-160.

Lamont-Mills, A., \& Christensen, S. A. (2006). Athletic identity and its relationship to sport participation levels. Journal of Science and Medicine in Sport, 9(6), 472-478.

Luhtanen, R., \& Crocker, J. (1992). A collective self-esteem scale: Selfevaluation of one's social identity. Personality and Social Psychology Bulletin, 18(3), 302-318.

Lim, S. Y., Warner, S., Dixon, M., Berg, B., Kim, C., \& Newhouse-Bailey, M. (2011). Sport participation across national contexts: A multilevel investigation of individual and systemic influences on adult sport participation. European Sport Management Quarterly, 11(3), 197224.

Little, D. E. (2002). Women and adventure recreation: Reconstructing leisure constraints and adventure experiences to negotiate continuing participation. Journal of Leisure Research, 34(2), 157-177.

Martin, J. J., Eklund, R. C., \& Mushett, C. A. (1997). Factor structure of the athletic identity measurement scale with athletes with disabilities. Adapted Physical Activity Quarterly, 14(1), 74-82.

Mean, L. J., \& Kassing, J. W. (2008). "I would just like to be known as an athlete": Managing hegemony, femininity, and heterosexuality in female sport. Western Journal of Communication, 72(2), 126-144.

Mennesson, C. (2000). Hard women and soft women: The social construction of identities among female 
boxers. International Review for the

Sociology of Sport, 35(1), 21-33.

Messner, M. A. (2002). Taking the field:

Women, men, and sports. Minneapolis,

MN: University of Minnesota Press.

Misener, K., Doherty, A., \& Hamm-Kerwin,

S. (2010). Learning from the

experiences of older adult volunteers

in sport: A serious leisure

perspective. Journal of Leisure Research, 42(2), 267-289.

Murphy, G. M., Petitpas, A. J., \& Brewer, B. W. (1996). Identity foreclosure, athletic identity, and career maturity in intercollegiate athletes. The Sport Psychologist, 10, 239-246.

Nasco, S. A., \& Webb, W. M. (2006).

Toward an expanded measure of athletic identity: The inclusion of public and private dimensions. Journal of Sport and Exercise Psychology, 28(4), 434-453.

Needham, M. D., Scott, D., \& Vaske, J. J. (2013). Recreation specialization and related Concepts in leisure research.

Leisure Sciences, 35(3), 199-202.

O'Connor, J. P., \& Brown, T. D. (2010).

Riding with the sharks: serious leisure cyclist's perceptions of sharing the road with motorists. Journal of Science and Medicine in Sport, 13(1), 53-58.

Patterson, I., \& Pegg, S. (2009). Serious leisure and people with intellectual disabilities: Benefits and opportunities. Leisure Science, 28(4), 387-402.
Paul, J. (2015). Sport and body empowerment: Female athletes' experiences with roller derby, mixed marital arts, and rugby. Journal of Alternative Perspective in Social Sciences, 6(4), 402-438.

Paul, J., \& Blank, S. (2015). The power and joy of derby: Women's participation, empowerment, and transformation in a flat-track roller derby team. Journal of Feminist Scholarship, 9, 51-72.

Pavlidis, A. (2012). From Riot Grrrls to roller derby? Exploring the relations between gender, music and sport. Leisure Studies, 31(2), 165-176.

Pavlidis, A., \& Fullagar, S. (2015). The pain and pleasure of roller derby: Thinking through affect and subjectification. International Journal of Cultural Studies, 18(5), 483-499.

Phoenix, C., Faulkner, G., \& Sparkes, A. C. (2005). Athletic identity and selfageing: The dilemma of exclusivity. Psychology of Sport and Exercise, 6(3), 335-347.

Raisborough, J. (2006). Getting onboard: women, access and serious leisure. The Sociological Review, 54(2), 242-262.

Ross, S. R., \& Shinew, K. J. (2008).

Perspectives of women college athletes on sport and gender. Sex Roles, 58(1), 40-57.

Roster, C. A. (2007). "Girl power" and participation in macho recreation: the case of female Harley riders. Leisure Sciences, 29(5), 443-461. 
Ryska, T. A. (2002). The effects of athletic identity and motivation goals on global competence perceptions of student-athletes. Child Study Journal, 32(2), 109-129.

Scott, D. (2012). Serious leisure and recreation specialization: An uneasy marriage. Leisure Sciences, 34(4), 366371.

Siegenthaler, K. L., \& O’Dell, I. (2003). Older golfers: Serious leisure and successful aging. World Leisure Journal, 45(1), 45-52.

Stebbins, R. A. (1992). Amateurs, professionals, and serious leisure. Canada: McGillQueen's Press.

Stebbins, R. A. (2001). Serious Leisure. Society, 38, 53-57.

Stebbins, R. A. (2006). Serious leisure: $A$ perspective for our time. New Brunswick: Transaction

Storms, C. E. (2008). "There's no sorry in roller derby": A feminist examination of identity of women in the full contact sport of roller derby'. The New York Sociologist, 3, 68-87.

Stryker, S., \& Burke, P. J. (2000). The past, present, and future of an identity theory. Social Psychology Quarterly, 63(4), 284-297.

Tasiemski, T., \& Brewer, B. W. (2011). Athletic identity, sport participation, and psychological adjustment in people with spinal cord injury. Adapted Physical Activity Quarterly, 28(3), 233-250.
Tsaur, S. H., \& Liang, Y. W. (2008). Serious leisure and recreation specialization. Leisure Sciences, 30(4), 325-341.

Vaske, J. J. (2008). Survey research and analysis: Applications in parks, recreation and buman dimensions. State College, PA: Venture Publishing.

Wachs, F. L. (2005). The boundaries of difference: Negotiating gender in recreational sport. Sociological Inquiry, 75(4), 527-547.

Women Flat Track Derby Association (2012). Roller derby demographics: Results from the third annual comprehensive data collection on skaters and fans. Retrieved from https://wftda.org/files/rollerderby-demographics-2012.pdf

Yopyk, D. J., \& Prentice, D. A. (2005). Am I an athlete or a student? Identity salience and stereotype threat in student-athletes. Basic and Applied Social Psychology, 27(4), 329-336. 


\section{Tables}

Table 1

Demographics and Behavioral Profile of Respondents

\begin{tabular}{|c|c|c|}
\hline Variables & Frequency & Percentage \\
\hline \multicolumn{3}{|l|}{ Age } \\
\hline $18-34$ & 400 & $69.2 \%$ \\
\hline $35-54$ & 178 & $30.8 \%$ \\
\hline \multicolumn{3}{|l|}{ Race } \\
\hline White & 535 & $92.6 \%$ \\
\hline Non-White & 43 & $7.4 \%$ \\
\hline \multicolumn{3}{|l|}{ Education } \\
\hline Less than Bachelor's & 184 & $31.8 \%$ \\
\hline Bachelor's or above & 394 & $68.2 \%$ \\
\hline \multicolumn{3}{|l|}{ Household income } \\
\hline$<\$ 55,000$ & 321 & $55.5 \%$ \\
\hline$\geq \$ 55,000$ & 257 & $44.5 \%$ \\
\hline \multicolumn{3}{|l|}{ Member of WFTDA* } \\
\hline Yes & 400 & $76.1 \%$ \\
\hline No & 132 & $22.8 \%$ \\
\hline \multicolumn{3}{|l|}{ Practice Frequency } \\
\hline Weekly* & 565 & $97.8 \%$ \\
\hline More than once & 7 & $1.2 \%$ \\
\hline Once & & \\
\hline \multicolumn{3}{|l|}{ Participated Bouts } \\
\hline \multicolumn{3}{|l|}{ Annually } \\
\hline Home bouts & $M=7.33 ; S D=4.01$ & \\
\hline Away bouts & $M=6.65 ; S D=4.78$ & \\
\hline
\end{tabular}

Note: * Three participants did not response "Member of WFTDA" and six did not response "Practice Frequency Weekly" 
Table 2

Pearson's Correlation between Serious Leisure and Participants' Demographics and Athletic Identity

\begin{tabular}{|c|c|c|c|c|c|c|}
\hline \multirow[b]{2}{*}{ Variables } & \multicolumn{4}{|c|}{ Demographics } & & \\
\hline & Age & Race & Education & \multicolumn{2}{|l|}{ Income } & \\
\hline Serious & 0.01 & -0.01 & $-0.11 * *$ & \multicolumn{2}{|l|}{$-0.16^{* *}$} & \\
\hline \multicolumn{7}{|l|}{ Leisure } \\
\hline Age & 1 & -0.06 & $-0.09 *$ & \multicolumn{2}{|l|}{$0.27 * *$} & \\
\hline Race & & 1 & -0.02 & \multicolumn{2}{|l|}{-0.03} & \\
\hline Education & & & 1 & \multicolumn{2}{|l|}{0.07} & \\
\hline Income & & & & \multicolumn{2}{|l|}{1} & \\
\hline \multirow[b]{2}{*}{ Variables } & \multicolumn{6}{|c|}{ Athletic Identity } \\
\hline & $\begin{array}{l}\text { Social } \\
\text { identity }\end{array}$ & Exclusivity & $\begin{array}{l}\text { Self- } \\
\text { identity }\end{array}$ & $\begin{array}{l}\text { Negative } \\
\text { aff. }\end{array}$ & $\begin{array}{l}\text { Positive } \\
\text { aff. }\end{array}$ & $\begin{array}{l}\text { Cronbach's } \\
\text { alpha }\end{array}$ \\
\hline $\begin{array}{l}\text { Serious } \\
\text { Leisure }\end{array}$ & $0.38^{* *}$ & $0.48^{* *}$ & $0.62^{* *}$ & $0.14 * *$ & $0.64 * *$ & 0.94 \\
\hline $\begin{array}{l}\text { Leisure } \\
\text { Social } \\
\text { identity }\end{array}$ & 1 & $0.49 * *$ & $0.48^{* *}$ & $0.27 * *$ & $0.36^{* *}$ & 0.69 \\
\hline Exclusivity & & 1 & $0.61 * *$ & $0.37 * *$ & $0.44^{* *}$ & 0.70 \\
\hline Self-identity & & & 1 & $0.29 * *$ & $0.60^{* *}$ & 0.71 \\
\hline $\begin{array}{l}\text { Negative } \\
\text { aff. }\end{array}$ & & & & 1 & $0.18^{* *}$ & 0.68 \\
\hline Positive aff. & & & & & 1 & 0.78 \\
\hline Mean & 4.02 & 3.76 & 4.09 & 3.97 & 4.42 & \\
\hline $\mathrm{SD}$ & .73 & .61 & .63 & .75 & .41 & \\
\hline
\end{tabular}

Note: $p<.05^{*}, p<.01^{* *}$ 
Table 3

Hierarchical Regression Predicting Roller Derby Women's Serious Leisure from Demographics and Athletic Identity

\begin{tabular}{|c|c|c|c|c|}
\hline \multirow[b]{3}{*}{ Variable } & \multicolumn{4}{|c|}{ Serious Leisure } \\
\hline & \multicolumn{2}{|c|}{ Model 1} & \multicolumn{2}{|c|}{ Model 2} \\
\hline & $B$ & $\beta$ & $B$ & $\beta$ \\
\hline \multicolumn{5}{|l|}{ Demographics } \\
\hline Age & .04 & .05 & .04 & .04 \\
\hline Race & -.01 & -.01 & -.02 & -.01 \\
\hline Education & -.08 & $-.10^{*}$ & -.02 & -.02 \\
\hline Family income & -.13 & $-.16^{*}$ & -.05 & $-.07 *$ \\
\hline \multicolumn{5}{|l|}{ Athletic identity } \\
\hline Social identity & & & .62 & $.09 * *$ \\
\hline Exclusivity & & & .09 & $.13^{* *}$ \\
\hline Self-identity & & & .17 & $.26 * *$ \\
\hline Negative affectivity & & & -.04 & $-.08^{*}$ \\
\hline Positive affectivity & & & .41 & $.50 * *$ \\
\hline $\mathrm{R}$ & .19 & & .81 & \\
\hline$R^{2}$ & $.04 * *$ & & $.65^{* *}$ & \\
\hline Change $R^{2}$ & & & $.61 * *$ & \\
\hline
\end{tabular}

